\title{
Effects of Different Curing Unites on Bulk Fill Composites
}

\author{
Koray Soygun ${ }^{1 *}$, Murat Unal' ${ }^{2}$, Ali Ozer ${ }^{3}$, Evrem Gulnahar ${ }^{4}$ and Giray Bolayır ${ }^{1}$ \\ ${ }^{1}$ Department of Prosthodontics, Faculty of Dentistry, Cumhuriyet University, Turkey \\ ${ }^{2}$ Department of Pedodontics, Faculty of Dentistry, Cumhuriyet University, Turkey \\ ${ }^{3}$ Department of Metallurgy and Material Engineering, Faculty of Engineering, Cumhuriyet University, Turkey \\ ${ }^{4}$ Department of Prosthodontics, Faculty of Dentistry, Erzincan University, Turkey
}

*Corresponding author: Koray Soygun, Department of Prosthodontics, Faculty of Dentistry, Cumhuriyet University, Sivas, Turkey, E-mail: koraysoygun@hotmail.com

\begin{abstract}
The aim of this study was to investigate three aged (with thermocycling and distilled water) bulk fill composites' (X-tra base, Surefil SDR flow, Tetric EvoCeram) surface microhardness levels $4 \mathrm{~mm}$ diameter and 2 or $4 \mathrm{~mm}$ thickness composites' samples were polymerized by a halogen light and a blue-light emitting diode $(n=10)$. A Vickers microhardness tester was used to evaluate the microhardness at the top and bottom surfaces of every specimen. When the measurements of bottom parts were evaluated, no significant difference was found in each composite group, except for X-tra base $2 \mathrm{~mm}$ thickness specimen polymerized with LED and halogen units. The specimen showing the highest microhardness was Tetric EvoCeram composite group. When the top surface parts were evaluated, microhardness levels of 2 or $4 \mathrm{~mm}$ thick X-tra base composite samples showed significant statistical difference. In other specimen groups, no such significant difference was observed. Microhardness level was influenced by the type of light source used. Microhardness levels at the bottom surface were found to be lower when compared to the levels of top surfaces for all materials tested.
\end{abstract}

\section{Keywords}

Aging, Resin composites, Dental curing light, Vickers hardness test, SEM

\section{Introduction}

Flowable composites are significant advancement in restorative dental materials. Low viscosity resin is the basis of flowable composites, and the resin is acquired from specific formulations which use $20-25 \%$ lesser filler loading compared to the traditional composites. Initially, flowable composites were used simply as liners, and the reason to that was their low elastic modulus. They are aimed to be used in bulk restorations by increasing mechanical properties $[1,2]$.

Restoring cavities with light-curing composites are viewed as the golden standard for applying and curing the resin composite in increments of limited thickness. Maximum increment thickness

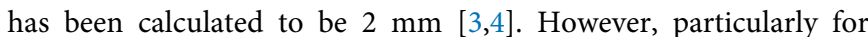
deep cavities, this is time-consuming and it can danger potential of air bubbles or contamination between the increments. Therefore, different manufacturers have recently produced new types of resin composites, which are called 'bulk fill' materials claimed to be curable to a maximum increment thickness of $4 \mathrm{~mm}$ [5]. In this study, microhardness levels of 3 different bulk fill composites after being polymerized with 2 different light devices were investigated.

Various parameters influencing the polymerization of resin composite must be considered for the improvement of generally used dental resins' clinical behaviour. The polymerization of light cured materials depends on their chemical composition, on the amount of filler particles, as well as on spectral output and irradiance of blue light emitted by light curing units (LCUs) [6-8]. Dentists may choose from different types of curing lights for the photo-polymerization of composites, such as conventional quartz tungsten-halogen (QTH/ HAL), light emitting diode (LED) curing units [9]. QTH/HAL is commonly preferred dental light curing unit [10]. It produces light via incandescence. For the restriction of the emitted light to the blue region of spectrum when polymerizing the resin composite, filters are needed. One of the benefits of using the QTH/HAL is its low cost technology, while one of the drawbacks of using these units is their limited lifetime. High operating temperatures and large amount of heat generated during the operation may cause bulb, reflector and filter to degrade over time [8].

LED curing lights in narrow band with peak emission of $470 \mathrm{~nm}$ use gallium nitride semiconductors that produce a blue light when subjected to an electrical current. Low energy consumption during light emitting process is one of the advantages of LEDs and it also enables them to be powered with rechargeable batteries [11-14].

Externally imposed variables, such as the temperature, oral media and mechanical loads determine the properties of a restorative composite material. Temperature sensitivity in the dental resin composites regarding the mechanical and tribological characterization is a subject that lacks research. There are few studies regarding the effect of temperature on mechanical properties aiming to apply this knowledge into products for clinical service [15].

The purpose of this study is to investigate the microhardness of three different bulk fill composites and the effect depending on the

\section{Clinmed International Library}

Citation: Soygun K, Unal M, Ozer A, Gulnahar E, Bolayır G (2015) Effects of Different Curing Unites on Bulk Fill Composites. Int J Oral Dent Health 1:013

Received: June 26, 2015: Accepted: August 06, 2015: Published: August 09, 2015 Copyright: ( 2015 Soygun K. This is an open-access article distributed under the terms of the Creative Commons Attribution License, which permits unrestricted use, distribution, and reproduction in any medium, provided the original author and source are credited. 
Table 1: The manufacturers, types, lots, matrix and filler systems of the bulk fill resin composites.

\begin{tabular}{|c|c|c|c|c|c|}
\hline Resin Composite & Manufacturer & Type & Lot number & Matrix & Filler System \\
\hline $\begin{array}{l}\text { Surefil } \\
\text { SDR flow }\end{array}$ & $\begin{array}{l}\text { Dentsply } \\
\text { Caulk, } \\
\text { Milford, DE, } \\
\text { USA }\end{array}$ & Bulk fill & 1101201 & $\begin{array}{l}\text { Ethoxylated bisphenol A } \\
\text { dimethacrylate, } \\
\text { TEGDMA }\end{array}$ & $\begin{array}{l}\text { Barium/strontiumaluminofluoroborosilicateglass( } 68 \% \\
\text { wt or } 44 \% \text { vol) }\end{array}$ \\
\hline $\begin{array}{l}\text { Tetric } \\
\text { EvoCeram }\end{array}$ & $\begin{array}{l}\text { Bulk-fill } \\
\text { Ivoclar } \\
\text { Vivadent, } \\
\text { Schaan, Liechtenstein }\end{array}$ & Bulk fill & R04686 & $\begin{array}{l}\text { Dimethacrylate } \\
\text { co-monomers }\end{array}$ & $\begin{array}{l}\text { Ba glass, YbF3, oxides and prepolymers }(80 \% \text { wt or } \\
60 \% \text { vol) }\end{array}$ \\
\hline X-tra base & $\begin{array}{l}\text { Voco, } \\
\text { Cuxhaven, } \\
\text { Germany }\end{array}$ & Bullk fill & 1220186 & MMA, Bis-EMA & Inorganic fillers ( $75 \%$ wt or $58 \%$ vol) \\
\hline
\end{tabular}

Table 2: Light curing units

\begin{tabular}{|l|l|l|}
\hline & Heliolux DLX & Ultralight PB-070 \\
\hline Light source & Halogen & LED \\
\hline Intensity $\left(\mathrm{mW} / \mathrm{cm}^{2}\right)$ & 750 & 1000 \\
\hline Energy density $\left(\mathrm{J} / \mathrm{cm}^{2}\right)$ & 30 & 10 \\
\hline Wavelength of emission $(\mathrm{nm})$ & $400-500$ & $440-480$ \\
\hline Curing time $(\mathrm{s})$ & 40 & 10 \\
\hline
\end{tabular}

changes of the light source, resin composite thickness and thermal cycling.

\section{Materials and Methods}

\section{Composites and light curing units}

In this study, three different bulk fill composites were selected. List of composites, manufacturers and compositions are shown in table 1 . The composites were polymerized with LCUs. LCUs used in this study are shown in detail in table 2 .

\section{Experimental design}

It was used to light units at two levels (Halogen light and LED) and resin composite thickness at two levels (2mm and $4 \mathrm{~mm}$ ). Experimental groups consisted of 120 resin composite discs assigned to 12 groups $(n=10)$. Microhardness test took place after thermal cycling was applied to all specimens.

\section{Light curing units}

The composites were cured with LCUs of a conventional quartz-tungsten-halogen lamp (QTH; Heliolux DLX, Ivoclar Vivadent, Schaan, Liechtenstein), a blue light emitting diode (LED; Ultralight PB-070, Fine Vision Electronics Co. Ltd., Sanchung City, Taipei County, Taiwan). Light intensities given by the light unit manufacturers, as well as energy densities and curing time recommended by the restorative manufacturers are listed in table 2 .

\section{Preparation of specimens}

120 disc specimens of resin composite were obtained from the placement of composite into a teflon mold of $4 \mathrm{~mm}$ diameter, $2 \mathrm{~mm}$ thickness which is confined between two opposing $4 \mathrm{~mm}$ polyester strips (Mylar, Moyco Union Broach, York, USA). A glass slide (1 mm thickness) was then placed on the mould and excess material was extruded. The composite surface was irradiated through the glass slide and Mylar Strip. After that, the Mylar strips were discarded and we kept teeth in distilled water for $24 \mathrm{~h}$. The specimens underwent 10.000 cycles in distilled water between 5 and $55^{\circ} \mathrm{C}$, with a dwell time of 30 seconds in each bath and a transfer time of 15 seconds between baths. Before the measurement of microhardness, the samples were polished flat using a sequence of 600-, 800-, and 1200- grit silicon carbide papers and Sof-Lex discs (3M ESPE, St. Paul, MN, USA). The specimens were blotted dry.

\section{Vickers microhardness test}

Depth of cure the composite was determined by microhardness tests.
Table 3: Mean and standart deviations $(S D, n=10)$ of VHN values and hardness ratios.

\begin{tabular}{|c|c|c|c|c|c|}
\hline \multicolumn{3}{|c|}{ Resin Composites } & \multirow{2}{*}{$\begin{array}{l}\text { Top Surface } \\
\text { Mean } \pm \text { SD } \\
31,20 \pm 0,44^{a}\end{array}$} & \multirow{2}{*}{$\begin{array}{l}\text { Bottom surface } \\
\text { Mean } \pm \text { SD } \\
25,60 \pm 0,54^{e, C} \\
\end{array}$} & \multirow{2}{*}{$\begin{array}{l}\text { Hardness Ratio } \\
\text { Mean } \pm \text { SD } \\
0,82 \pm 0,01\end{array}$} \\
\hline \multirow{4}{*}{$\begin{array}{l}\text { Surafil SDR } \\
\text { flow }\end{array}$} & \multirow[t]{2}{*}{ LED } & $2 \mathrm{~mm}$ & & & \\
\hline & & $4 \mathrm{~mm}$ & $32,20 \pm 0,83$ & $19,40 \pm 1,14^{\mathrm{f}, \mathrm{C}}$ & $0,60 \pm 0,04$ \\
\hline & \multirow[t]{2}{*}{ Halogen } & $2 \mathrm{~mm}$ & $33,60 \pm 1,14^{a}$ & $28,60 \pm 0,54^{e, D}$ & $0,85 \pm 0,04$ \\
\hline & & $4 \mathrm{~mm}$ & $32,00 \pm 1,41$ & $25,20 \pm 0,44 \mathrm{f}, \mathrm{D}$ & $0,78 \pm 0,03$ \\
\hline \multirow[t]{4}{*}{ X-tra base } & \multirow[t]{2}{*}{ LED } & $2 \mathrm{~mm}$ & $49,20 \pm 1,92^{\mathrm{b}, \mathrm{A}}$ & $45,80 \pm 0,83^{E}$ & $0,93 \pm 0,04$ \\
\hline & & $4 \mathrm{~mm}$ & $43,40 \pm 1,14^{\mathrm{d}, \mathrm{A}}$ & $36,00 \pm 1,00^{g, E}$ & $0,82 \pm 0,01$ \\
\hline & \multirow[t]{2}{*}{ Halogen } & $2 \mathrm{~mm}$ & $46,60 \pm 1,14^{\mathrm{b}, \mathrm{B}}$ & $45,00 \pm 1,22$ & $0,96 \pm 0,02$ \\
\hline & & $4 \mathrm{~mm}$ & $49,00 \pm 1,00^{\mathrm{d}, \mathrm{B}}$ & $45,20 \pm 1,30^{9}$ & $0,92 \pm 0,03$ \\
\hline \multirow{4}{*}{$\begin{array}{l}\text { Tetric } \\
\text { EvoCeram }\end{array}$} & \multirow[t]{2}{*}{ LED } & $2 \mathrm{~mm}$ & $54,80 \pm 0,83^{c}$ & $48,20 \pm 3,34^{\mathrm{h}, \mathrm{F}}$ & $0,87 \pm 0,05$ \\
\hline & & $4 \mathrm{~mm}$ & $54,60 \pm 1,40$ & $41,20 \pm 1,30^{k, F}$ & $0,75 \pm 0,03$ \\
\hline & \multirow[t]{2}{*}{ Halogen } & $2 \mathrm{~mm}$ & $58,20 \pm 1,34^{c}$ & $52,60 \pm 2,19^{h}$ & $0,92 \pm 0,15$ \\
\hline & & $4 \mathrm{~mm}$ & $56,80 \pm 5,44$ & $50,00 \pm 2,44^{k}$ & $0,88 \pm 0,11$ \\
\hline
\end{tabular}

*Same superscripts statistically indicate significant differences between groups $(p \leq 0.05)$

By means of a digital microhardness tester (Shimadzu HMV-M3, Kyoto, Japan), a $300 \mathrm{~g}$ load was applied through the Vickers identor with a dwell time of 15 seconds. Three indentations were made at top and bottom surfaces respectively, and the measurements were done at different parts of each specimen. After this step, Vickers hardness number (VHN) and hardness ratio was calculated and tabulated using the following formula: Hardness ratio $=\mathrm{HN}$ of bottom surface/VHN of top surface.

\section{Statistical analysis}

The mean microhardness levels and standard deviations were calculated by using SPSSTM Statistical Software (SPSS version 14.0 software, SPSS Inc, Chicago, IL, USA). Data were then analyzed by Kruskall Wallis and Mann Whitney $U$ tests were used and margin of error was calculated as 0.05 .

\section{Scanning electron microscope (SEM) observation}

In order to clarify the size and distribution of tested filler particles belonging to resin bulk fill composites, a specimen of $1 \mathrm{~mm}$ thickness and $4 \mathrm{~mm}$ diameter was taken from each material in the same day for the microhardness test and these specimens were cured with QTH LCU. The top surface of each specimen was polished as described above and the surfaces were examined under SEM. Specimens were then made conductive with the effect of vacuum at $4 \times 10-2 \mathrm{mbar}$ in a Polaron SC7620 Sputter Coater which coated the specimens with AuPd for 15s (3 Angstrom coating per second, in total 45 Angstrom). Then, photomicrographs were taken using a scanning electron microscope (SEM) (LEO 440 Scanning Electron Microscope, UK).

\section{Results}

The means and standard deviations of VHN values belonging to top and bottom surfaces are shown in table 3. Hardness ratios obtained after polymerizing resin composite with both light curing units are also shown in the same table. 


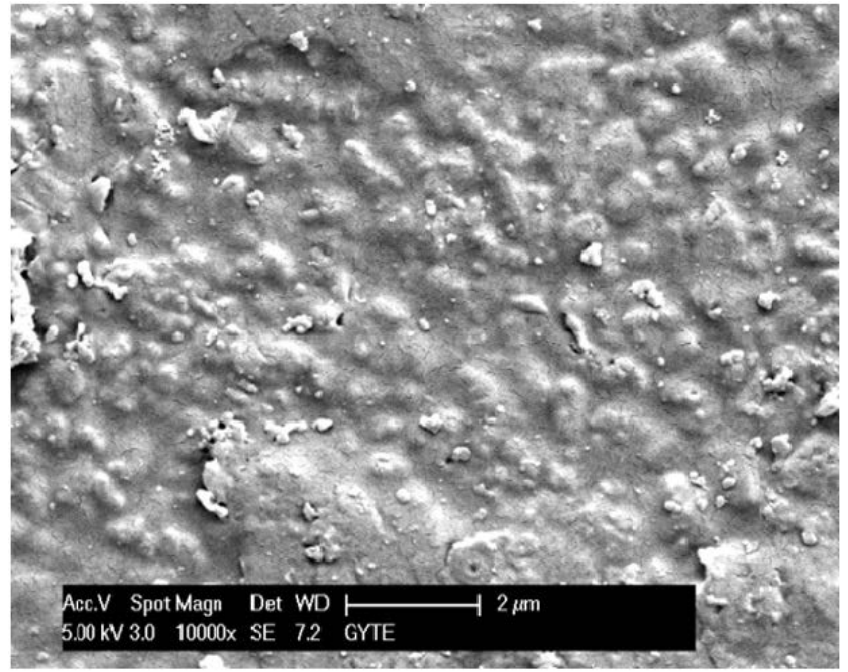

Figure 1: SEM view of Tetric EvoCeram Bulk fill resin composite specimen cured with LED at $\mathrm{X} 10,000$ magnification.

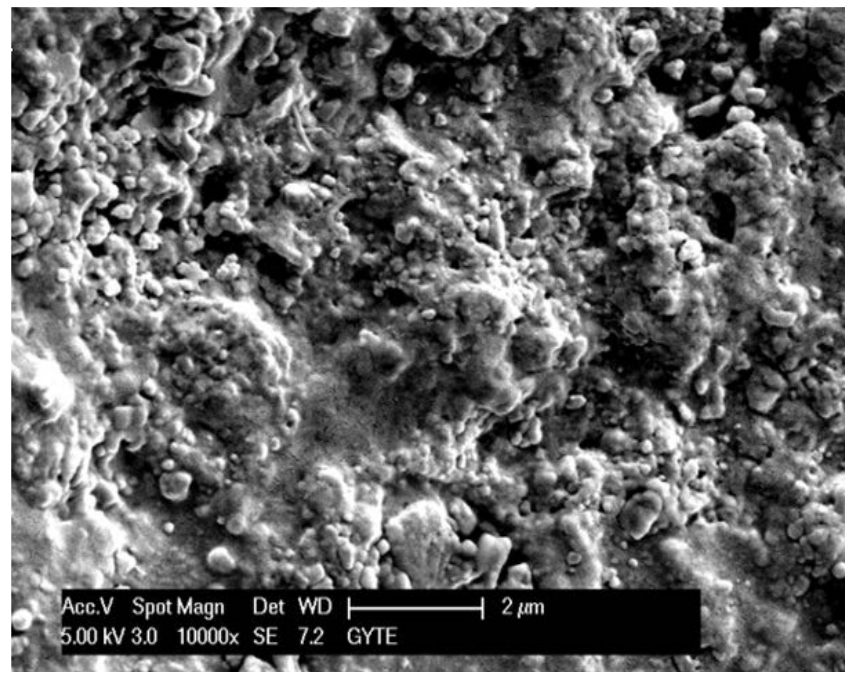

Figure 2: SEM view of $X$-tra base Bulk fill resin composite specimen cured with LED at $\mathrm{X} 10,000$ magnification.

All of the materials were cured with the two light sources and the values obtained for the bottom surfaces were found to be lower than the values of top surfaces. When considering the curing efficiency of different light curing units at top surfaces of given composite materials, there were significant statistical differences among the microhardness levels of materials cured with LED and Halogen $(\mathrm{p}<0.05)$, except for SDR and Tetric EvoCeram composites of $4 \mathrm{~mm}$ thickness. Microhardness level among the specimen groups which were polymerized with halogen light source was higher than the specimens which were polymerized with LED light source. Highest microhardness level among all composite materials belonged to Tetric EvoCeram composite group, whereas lowest microhardness level was of SDR composite specimens.

When the bottom surface microhardness levels were evaluated, a significant difference was discovered between all composite groups, expect for the X-tra base specimen group of $2 \mathrm{~mm}$ thickness which was polymerized with both halogen and LED light sources $(\mathrm{p}<0.05)$ Highest microhardness levels was observed at Tetric EvoCeram composite group.

A significant difference between the top surface microhardness levels of $2 \mathrm{~mm}$ and $4 \mathrm{~mm}$ thick specimens of X-tra base composite group was found after the statistical evaluation based on the thicknesses of composite specimens. There were no such significant differences between the microhardness levels of other specimens.

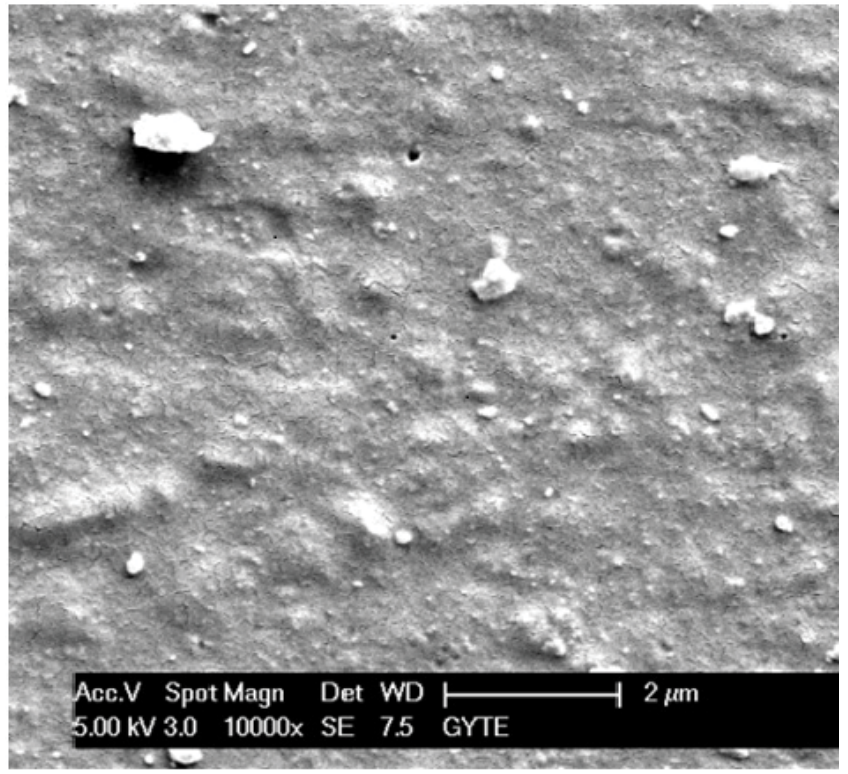

Figure 3: SEM view of Surefil SDR flow Bulk fill resin composite specimen cured with LED at $\mathrm{X} 10,000$ magnification.

When the microhardness levels of bottom surfaces were compared, the difference between $2 \mathrm{~mm}$ and $4 \mathrm{~mm}$ thick specimens of X-tra base and Tetric EvoCeram composite groups which were polymerized by halogen light was found to be insignificant, whereas the differences between other specimen groups were found to be significant.

Hardness ratio range was between $0.60 \pm 0.04$ and $0.96 \pm$ 0.02 . Hardness ratio value was found to be higher than 0.80 for all composite groups, excluding the SDR composite groups of $4 \mathrm{~mm}$ thickness, polymerized with both halogen and LED light sources and $4 \mathrm{~mm}$ thick Tetric EvoCeram composite group, polymerized with LED light source.

When SEM images were observed (Figure 1-3), different surface views of all composite specimens were found. Indentations were seen on the surface of SDR bulk fill composite specimen. Tetric EvoCeram group's specimens had big and small particles on the surface, with big particles showing no homogeneous distribution, whereas X-tra base specimens showed a surface with homogeneous distribution of small particles, with a rugged surface.

\section{Discussion}

Factors significantly affecting the hardness values of restorative materials are; filler volume fraction, composition, resin type and polymerization degree. After the polymerization process, monomers that not participating in reactions cause a decrease in the hardness levels, and the hardness of the inorganic fillers directly affect the overall microhardness level of the materials [16]. In order to avoid toxic monomer's release, it is required to achieve the highest degree of conversion through the curing of the composite via a light source. As Yearn [17] has specified in his work, evaluation of resin composite polymerization can be applied using several methods. Examination of hardness level also shows the degree of conversion and this is why these tests are crucial $[18,19]$ Traditionally, three main hardness tests were proposed for testing the hardness level of resin composite (Barcol, Knoop and Vickers) [18]. In this study, the Vickers hardness test was used, as done in previous studies $[6,7,14]$.

In oral cavities, the range and gradient of temperature changes are usually found to be complicated. In most cases, consumed food and individual's dietary habits affect the temperature in the mouth. In this study, thermocycling was used as an instrument to mimic the individual's mouth. Even though repeated heating and cooling in $55^{\circ} \mathrm{C}$ and $5^{\circ} \mathrm{C}$ baths were performed, it must be mentioned that this process was not complicated enough to mimic the real oral environment. Moreover, 10,000 thermocycles taken place in this study were also 
arbitrary. Nonetheless, 10,000 is a frequently chosen repeat number for thermocycle applications [20].

Regardless of the light curing units (LCU) used; bottom surface hardness values were lower than those of the top surface in all tested materials. Topcu et al. [7] state in their study that, bottom surface microhardness levels are lower than top surface microhardness levels in all specimens polymerized with both LED and halogen light sources. In this study, sufficient light was used to activate the photoinitiator [21], and no overlying composites to interfere with light transmission (as described in the preparation of specimens) were in the environment. For this reason, it was found that composite cure at the top surface was not dependent to the light intensity of the bottom surface. As light passes through the body of a composite, its intensity is greatly decreased due to the absorption and dispersion of light by filler particles and resin matrix. This decrease results in a gradation of cure; causing a decrease in the hardness level from the top surface to inwards. This fact explains the difference between top surface hardness levels and bottom surface hardness levels in all the materials cured with two light sources. Different hardness levels in different materials can be explained with their different filler contents. The fact that higher filler proportion makes an object to be penetrated by light more difficultly also explains this situation [22,23].

It has been suggested that both bottom and top surface hardness levels are crucial criteria during the verification of cure efficiency in deeper areas when they are compared to the surface closest to the light source. Theoretically, hardness level at the bottom surface of a cured resin composite should be at least $80 \%(0.8)$ of the hardness of the top surface [23]. Hardness levels lower than 0.8 were measured when SDR composite groups of $4 \mathrm{~mm}$ thickness polymerized with QTH and LED light sources, as well as Tetric EvoCeram composite groups polymerized with LED light sources were examined. Low hardness levels can be explained with the ingredients of composites and the features of light sources used for polymerization.

In their work regarding the mechanical features of new generation flowable composites, Salerno et al. state that SDR composites have lower hardness levels when compared with other composites. Flury et al. researching the polymerization depth of composites have concluded that Surefill SDR and Venus Bulkfill composites have lower hardness levels. Lower hardness level for SDR composites may be explained with fillers sinking-in during the indentation process, which is caused by incomplete curing or poor filler resin bonding, or by a combination of both causes. Therefore, another reason explaining the low hardness levels may be the lower molecular weight and volume ratio of these fillers in matrix when compared to other composites ( $68 \%$ by wt and $44 \%$ by vol) [24].

In scope of the study, highest microhardness levels regardless of light sources were observed in Tetric EvoCeram bulk fill composite group. In light of the studies conducted on this matter, it is generally assumed that if the filler loading level is higher, composite mechanical properties are higher as well. In accordance with this information, it is possible to state that high molecular weight and volume ratio of this composite holds when compared to other composites has an effect on this result. When SEM images belonging to composites are viewed, the difference in the distribution and dimensions of particles in matrix can be seen (Figure 1-3).

In his work, Hammouda [25] states that microhardness levels of composite specimens polymerized with LED light sources are higher than the composites polymerized with halogen light sources. Rode et al. [26] during their studies, have measured the microhardness levels of resin composite specimens of 2, 3 and $4 \mathrm{~mm}$ thickness. It was discovered that microhardness levels of 3 or $4 \mathrm{~mm}$ thick and polymerized with halogen light specimens are significantly higher than the ones prepared with LED light source. In their work, Dunn and Bush [27] state that both top and bottom surface microhardness levels of composite specimens polymerized with halogen light sources are higher than the specimens polymerized with LED light sources. In this research conducted, we have also discovered that the microhardness level of the specimens which were polymerized with halogen light sources were higher. This fact parallels our study's conclusions with other researchers' $[8,11]$ conclusions. The reason why for the halogen light being a better polymerization tool is that halogen light sources have higher energy density when compared to LED light sources and that halogen light sources have longer application time. These reasons lead to a better polymerization, thus to a higher microhardness level.

\section{Conclusion}

Through the results of this study, it was concluded that, among the tested bulk fill composites, Tetric EvoCeram showed the highest microhardness level regardless of the LCUs used. Microhardness was influenced by the type of light source used. Microhardness levels at the bottom surface were found to be lower when compared to the level of top surfaces for all materials tested.

\section{References}

1. Rada RE (1998) The versatility of flowable composites. Dent Today 17: 7883

2. Bayne SC, Thompson JY, Swift EJ Jr, Stamatiades P, Wilkerson M (1998) A characterization of first-generation flowable composites. J Am Dent Assoc 129: $567-577$.

3. Perdigão J, Anauate-Netto $C$, Carmo AR, Hodges JS, Cordeiro HJ, et al. (2004) The effect of adhesive and flowable composite on postoperative sensitivity: 2-week results. Quintessence Int 35: 777-784

4. Sakaguchi RL, Douglas WH, Peters MC (1992) Curing light performance and polymerization of composite restorative materials. J Dent 20: 183-188.

5. Pilo R, Oelgiesser D, Cardash HS (1999) A survey of output intensity and potential for depth of cure among light-curing units in clinical use. J Dent 27 235-241.

6. (2009) Surefil SDR flow posterior bulk fill flowable base. United States: Inside Dentistry, in pactise, Tech Profile.

7. Hubbezoglu I, Bolayir G, Dogan OM, Dogan A, Ozer A, et al. (2007) Microhardness evaluation of resin composites polymerized by three different light sources. Dent Mater J 26: 845-853.

8. Topcu FT, Erdemir U, Sahinkesen G, Yildiz E, Uslan I, et al. (2010) Evaluation of microhardness, surface roughness, and wear behavior of different types of resin composites polymerized with two different light sources. J Biomed Mater Res B Appl Biomater 92: 470-478.

9. Yaman BC, Efes BG, Dörter C, Gömeç Y, Erdilek D, et al. (2011) The effects of halogen and light-emitting diode light curing on the depth of cure and surface microhardness of composite resins. J Conserv Dent 14: 136-139.

10. Price RB, Ehrnford L, Andreou P, Felix CA (2003) Comparison of quartztungsten-halogen, light-emitting diode, and plasma arc curing lights. J Adhes Dent 5: 193-207.

11. Park SH, Kim SS, Cho YS, Lee SY, Noh BD (2005) Comparison of linear polymerization shrinkage and microhardness between QTH-cured \& LEDcured composites. Oper Dent 30: 461-467.

12. Franco EB, Lopes LG (2003) Conceitos atuais na polimerização de sistemas restauradores resinosos. Biodonto 1: 10-59.

13. Asmussen E, Peutzfeldt A (2003) Light-emitting diode curing: influence on selected properties of resin composites. Quintessence Int 34: 71-75.

14. Voltarelli FR, dos Santos-Daroz CB, Alves MC, Peris AR, Marchi GM (2009) Effect of different light-curing devices and aging procedures on composite knoop microhardness. Braz Oral Res 23: 473-479.

15. Ramalho A, Braga de Carvalho, Antunes PV (2013) Effects of temperature on mechanical and tribological properties of dental restorative composite materials. Tribology Inter 63: 186-95.

16. Asmussen $E$ (1982) Factors affecting the quantity of remaining double bonds in restorative resin polymers. Scan J Dent Res 90: 490-496.

17. Yearn JA (1985) Factors affecting cure of visible light activated composites. Int Dent J 35: 218-225.

18. Rueggeberg FA, Craig RG (1988) Correlation of parameters used to estimate monomer conversion in a light-cured composite. J Dent Res 67: 932-937.

19. Ferracane $\mathrm{JL}$ (1985) Correlation between hardness and degree of conversion during the setting reaction of unfilled dental restorative resins. Dent Mater 1 : $11-14$.

20. Gale MS, Darvell BW (1999) Thermal cycling procedures for laboratory testing of dental restorations. J Dent 27: 89-99.

21. Yoon TH, Lee YK, Lim BS, Kim CW (2002) Degree of polymerization of resin composites by different light sources. J Oral Rehabil 29: 1165-1173. 
22. Neo BJ, Soh MS, Teo JW, Yap AU (2005) Effectiveness of composite cure associated with different light-curing regimes. Oper Dent 30: 671-675.

23. Salerno M, Derchi G, Thorat S, Ceseracciu L, Ruffilli R, et al. (2011) Surface morphology and mechanical properties of new-generation flowable resin composites for dental restoration. Dent Mater 27: 1221-1228.

24. Flury S, Hayoz S, Peutzfeldt A, Hüsler J, Lussi A (2012) Depth of cure of resin composites: is the ISO 4049 method suitable for bulk fill materials? Dent Mater 28: 521-528.
25. Hammouda IM (2010) Effect of light-curing method on wear and hardness of composite resin. J Mech Behav Biomed Mater 3: 216-222.

26. Rode KM, de Freitas PM, Lloret PR, Powell LG, Turbino ML (2009) Microhardness evaluation of a micro-hybrid composite resin light cured with halogen light, light-emitting diode and argon ion laser. Lasers Med Sci 24: 87-92.

27. Dunn WJ, Bush AC (2002) A comparison of polymerization by light-emitting diode and halogen-based light-curing units. J Am Dent Assoc 133: 335-341. 